\section{Localization of Peroxidase in Grapes using Nitrocellulose Blotting of Freezing/Thawing Fruits}

\author{
Antonio A. Calderón, J ose M . Z apata, R omualdo M uñoz, and \\ A. R os Barceló \\ Department of Plant Biology (Plant Physiology), University of Murcia, \\ E-30100 Murcia, Spain
}

Additional index words. isoenzymes, skin, tissue fractionation, Vitis vinifera

\begin{abstract}
A technique has been developed to study the histochemical localization of peroxidase in Vitis vinifera by blotting freezing/thawing tissue sections on nitrocellulose membranes. After being stained with 4-methoxy- $\alpha$-naphthol and $\mathrm{H}_{2} \mathrm{O}_{2}$, peroxidase-mediated reaction products in mature 'Gamay' grapes were seen principally in the skin and, to a lesser extent, the pericarp, where discrete areas of reaction products were located in the vascular bundles. However, for immature 'Gamay' and 'Grenache' grapes, peroxidase activity in the skin was low and similar to that found in the pericarp. With this technique, fruit vascular bundle structure was preserved. The reliability of the technique in the histochemical localization of peroxidase in grapes was confirmed by fractionation and determining the peroxidase activity in the various tissues.
\end{abstract}

Peroxidase (EC 1.11.1.7) is an enzyme studied widely in plants, and there is extensive literature describing changes in peroxidase activity and isoenzyme spectra as a function of ontogenic change and stress and as a specific characteristic of plant varieties and cultivars (Haard, 1977). Little effort, however, has been directed to understanding a physiological function for this enzyme.

Recently, it has been proposed that peroxidase may participate in the hydrogen peroxide-dependent metabolism of phenols (phenolic acids and flavonoids) in the vacuole (Takahama, 1991). In the grape cultivar Gamay, it has been shown that peroxidase, in conjunction with $\beta$-glucosidases, may be responsible for anthocyanin turnover and degradation (Calderón et al., 1992a). This observation is supported by the co-localization of peroxidase and anthocyanins in grapevine vacuoles (Calderón et al., 1992b). To clarify this possible role of peroxidases, histochemical studies of peroxidase in grapes are necessary, since it is well known that anthocyanins are located mainly in the epidermal and the subepidermal cell layers that constitute the berry skin (Moskowitz and Hrazdina, 1981).

Tissue printing has become an important tool invisualizing enzyme localization in plant tissues (Spruce et al., 1987). This technique

Received for publication 13 Feb. 1992. Accepted for publication 14 Sept. 1992. This work was in part supported by a grant from the CICYT (Spain), project no. AGR 296/89. A.A. Calderón holds a fellowship (BPPI) from the MEC (Spain). We thank A. Martínez-Cutillas and J. Carreño-Espín (CRIA, Murcia, Spain) for providing the grape berries. The cost of publishing this paper was defrayed in part by the payment of page charges. Under postal regulations, this paper therefore must be hereby marked advertisement solely to indicate this fact.

${ }^{1}$ To whom reprint requests should be addressed. teins (Nibbering et al., 1986), and subsequently detecting enzyme activities on the blots using simple histochemical procedures. However, using this technique to localize enzymes in fleshy fruits is limited, since the tissue has to be hard or stretched so that cross sections can be obtained easily. Thus, it is difficult to blot grape berry sections on nitrocellulose membranes because of the near impossibility of obtaining thin sections without tearing the tissues. To avoid this problem, we have developed a technique that consists of cutting frozen tissues. After thawing, the sections are blotted on nitrocellulose membranes. A histochemical peroxidase-staining technique on blotted tissues was developed using 4-methoxy- $\alpha$ - naphthol (4-MN) as a specific substrate, since it is not oxidizable by other hemoproteins (Ferrer et al., 1990). The results, confirmed by tissue fractionation, show that most peroxidase activity in mature grapes is located in the skin of the berry, as are the anthocyanins.

Plant material and tissue printing. 'Gamay' rouge and 'Grenache' were grown in the field at the Hacienda Nueva Viticultural Experimental Station of the CRIA (Murcia, Spain), and sampled before (immature grapes) and after (mature grapes) veraison (pigmentation). Clusters were transported to the laboratory

nitrocellulose membranes, using the prop ties of nitrocellulose to absorb and retain pro-
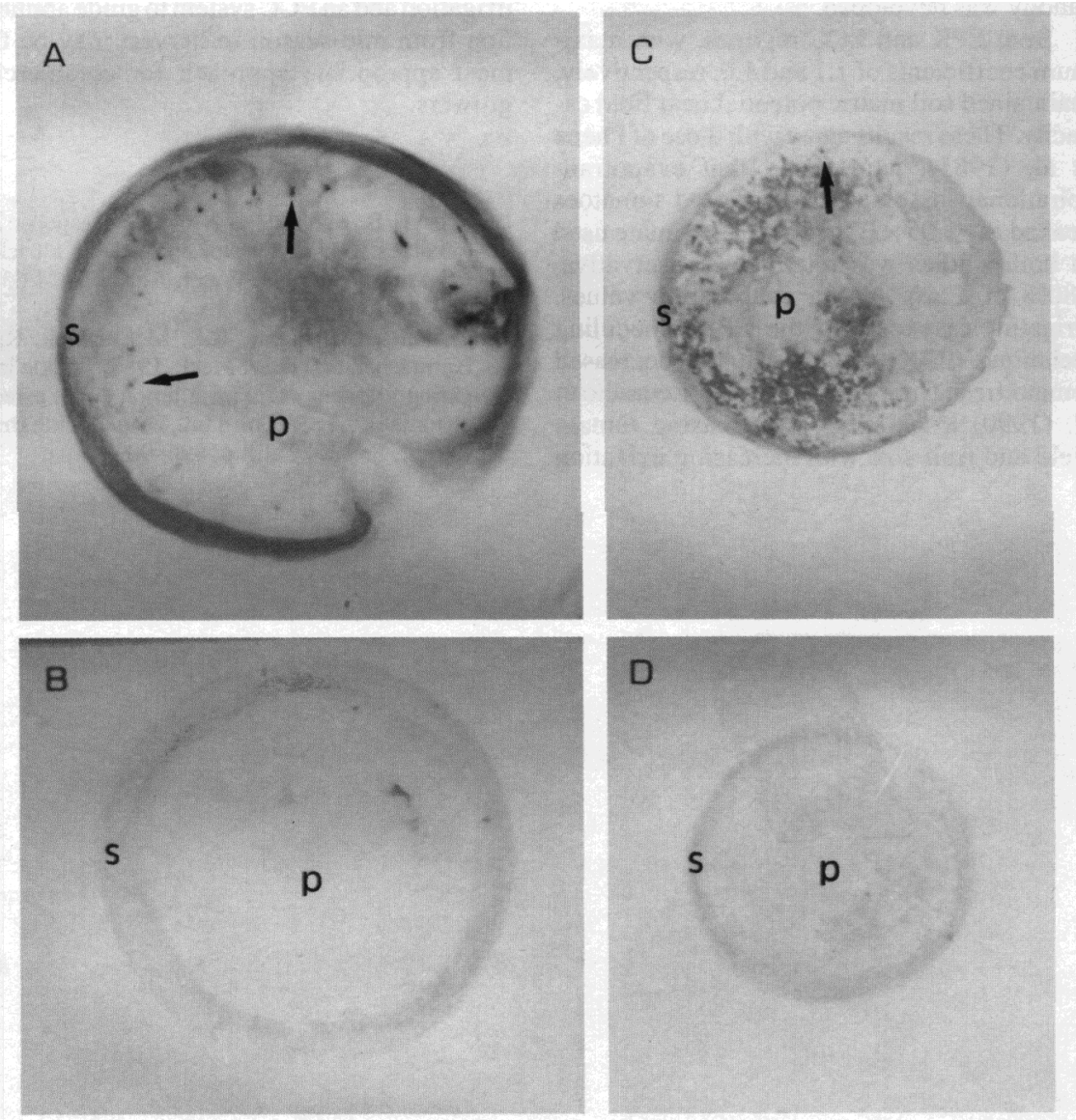

ig. 1. Histochemical blot of thawing sections of mature 'Gamay' grape berries after staining with 4-MN and $\mathrm{H}_{2} \mathrm{O}_{2}(\mathbf{A})$. Control in the absence of $\mathrm{H}_{2} \mathrm{O}_{2}($ B). Histochemical blot of thawing sections of immature 'Grenache' grape berries after staining with 4-MN and $\mathrm{H}_{2} \mathrm{O}_{2}\left(\right.$ C). Control in the absence of $\mathrm{H}_{2} \mathrm{O}_{2}($ D). s, skin; p, pericarp. 
Table 1. Tissue distribution of peroxidase activity in 'Gamay' and 'Grenache' grape berries in skin and pericarp after fractionation.

\begin{tabular}{lcc}
\hline \hline & \multicolumn{2}{c}{$\begin{array}{c}\text { Peroxidase activity } \\
\text { (pkat } \times \text { g tissue fresh wt) }\end{array}$} \\
\cline { 2 - 3 } Cultivar & Skin & Pericarp \\
\hline Gamay, mature & $950 \pm 40$ & $307 \pm 15$ \\
Gamay, immature & $92 \pm 12$ & $75 \pm 0$ \\
Grenache, immature & $111 \pm 28$ & $82 \pm 9$ \\
\hline
\end{tabular}

${ }^{z}$ Mean values \pm SE of three independent determinations. pkat $=$ pmoles substrate oxidized $/ \mathrm{sec}$.

and frozen immediately at $-30 \mathrm{C}$ for later analysis.

For tissue printing, dry $0.45-\mu \mathrm{m}$ nitrocellulose membrane filters (Bio-Rad, Richmond, Calif.) were placed on microscope slides and blotted with a tissue section. Thin grape sections were cut from the opposite extremity to the pedicel of frozen grapes freehand with a scalpel and the sections thawed at 25C. Thawing sections were placed and lightly pressed for $30 \mathrm{sec}$ on the membrane. The sections were removed carefully, and the dry membrane was incubated at $25 \mathrm{C}$ in a solution containing 1.0 $\mathrm{mm}$ 4-MN, $1.0 \mathrm{mM} \mathrm{H}_{2} \mathrm{O}_{2}$, and $0.1 \mathrm{M}$ tris [tris-(hydroxymethyl)-aminomethane]-acetate buffer, pH 5.0 (Ferrer et al., 1990), for 5 (mature grapes) or $20 \mathrm{~min}$ (immature grapes). Controls were carried out in the absence of $\mathrm{H}_{2} \mathrm{O}_{2}$ and in the presence of $50 \mu \mathrm{M}$ 2,4,6-cycloheptatriene-1-one (tropolone; Sigma, St. Louis). After being stained, the membranes were rinsed with distilled water and air-dried.

Tissue fractionation and peroxidase analysis. The skin and seeds were removed from the frozen grapes. The skin and flesh (pericarp) samples were homogenized in a mortar with pestle at $4 \mathrm{C}$ in the presence of 50 mM ammonium tartrate, $6 \mathrm{~mm}$ ascorbic acid, 1 $\mathrm{M} \mathrm{LiCl}, 250 \mathrm{~mm}$ tris-HCl buffer, $\mathrm{pH}$ 7.5, and $100 \mathrm{mg}$ polyvinylpolypyrrolidone (Sigma) per gram of fresh tissue. The homogenate was centrifuged at $20,000 \times g$ for $15 \mathrm{~min}$ and the supernatant dialyzed overnight against $50 \mathrm{~mm}$ tris-HCl buffer, $\mathrm{pH}$ 7.5. The dialyzed extracts constituted the soluble protein fraction used in the subsequent studies.

Peroxidase activity in the soluble protein fractions obtained from the skin and pericarp samples was determined by using $1.0 \mathrm{~mm}$ 4-MN and $1.0 \mathrm{~mm} \mathrm{H}_{2} \mathrm{O}_{2}$ in $100 \mathrm{~mm}$ tris-acetate buffer, pH 5.0 (Ferrer et al., 1990). Enzyme amounts were expressed in nanokatals using a $\varepsilon_{593}=2.1 \times 10^{4} \mathrm{M}^{-1} \cdot \mathrm{cm}^{-1}$ for the dye product.

The peroxidase isoenzymes were separated by isoelectric-focusing as described (Calderón et al., 1990). The peroxidase isoenzymes were stained with 4-MN using 1.0 mM 4-MN and $1.0 \mathrm{~mm} \mathrm{H}_{2} \mathrm{O}_{2}$ in $100 \mathrm{~mm}$ tris-acetate buffer, $\mathrm{pH}$ 5.0 (Ferrer et al., 1990).

In mature 'Gamay' grapes, blotting freezing/thawing sections on nitrocellulose membranes and subsequent staining with 4-MN/ $\mathrm{H}_{2} \mathrm{O}_{2}$ for $5 \mathrm{~min}$ revealed that most of the peroxidase activity occurred in the berry skin (Fig. 1A) and, secondarily, in the pericarp, where discrete areas for the reaction products may be seen at the concentric array of the vascular bundles (Fig. 1A, arrows). These reactions were sensitive to the absence of $\mathrm{H}_{2} \mathrm{O}_{2}$ (Fig. 1B) and insensitive to the presence of 50 $\mu \mathrm{M}$ tropolone (data not shown), a well-known and specific inhibitor of grape polyphenoloxidase (Valero et al., 1991) that helps differentiate polyphenoloxidase and peroxidase activities (Kahn, 1985).

Blotting freezing/thawing immature 'Grenache' berries on nitrocellulose membranes and subsequent staining with 4-MN/ $\mathrm{H}_{2} \mathrm{O}_{2}$ for 20 min led to similar results (Fig. 1C), although, in this case, the reaction observed in the pericarp was similar in intensity to that observed in skin. Unlike mature 'Gamay' berries, immature 'Grenache' berries required incubation for $20 \mathrm{~min}$ to develop peroxidase activity due to the low level of this enzyme found in grapes (Table 1). Again, the dye reactions were sensitive to the absence of $\mathrm{H}_{2} \mathrm{O}_{2}$ (Fig. 1D) and insensitive to the presence of tropolone (data not shown). These reactions, therefore, must be assigned to peroxidase activities.

Tissue-specific peroxidase localization in 'Gamay' (mature) berries was different than that in 'Grenache' (immature) berries due to different degrees of maturation. Thus, in immature 'Gamay' berries, in which the level of peroxidase activity was also low (Table 1) and similar to that found in the immature 'Grenache' berries (Table 1), the peroxidase stain intensity in the skin was weak and similar to that found in the pericarp (data not shown).

Blotting freezing/thawing grape sections did not damage vascular structure; concentric distribution of the vascular bundles was observed in the cross sections (Fig. $1 \mathrm{~A}$ and $\mathrm{C}$, arrows). These results suggest that blotting freezing/thawing tissues followed by histochemical staining may be a valuable tool in localizing peroxidase in grapes. This suggestion is supported by the fact that the staining intensity in enzyme blotting directly correlates with the amount of peroxidase incorporated into nitrocellulose membranes (Nibbering et al., 1986). However, Abeles and Biles (1991) have suggested that tissue printing may lead to confusing enzyme localization results, since enzymes may be missing from tissue blots because they are not free to move from the tissue to the blotting matrix.

We checked this possibility by fractionating 'Gamay' and 'Grenache' berries and individually homogenating the skin, which consists of the epidermis and several layers of hypodermal cells with thickened walls (Pratt, 1971), and the flesh (pericarp) so that we could determine peroxidase activity associated with the respective tissues. Peroxidase activity in 'Gamay' was greater in the skin than in the pericarp (Table 1), in accordance with the results obtained from tissue blotting (Fig. 1A). Likewise, in 'Grenache', the level of peroxidase activity in the skin was similar to that found in the pericarp (Table 1), in accordance with the results obtained from tissue blotting (Fig. 1C). The difference in peroxidase activity between 'Gamay' and 'Grenache' might be due to the difference in maturation at harvest. That peroxidase in grape berries increases with fruit maturation (pigmentation) degree (Kochhar et al., 1979) is well known; the increases are associated mainly with changes in the skin (Table 1).

Peroxidase isoenzyme patterns are frequently tissue-specific (Hertig et al., 1991; Lagrimini et al., 1987). For this reason, per-

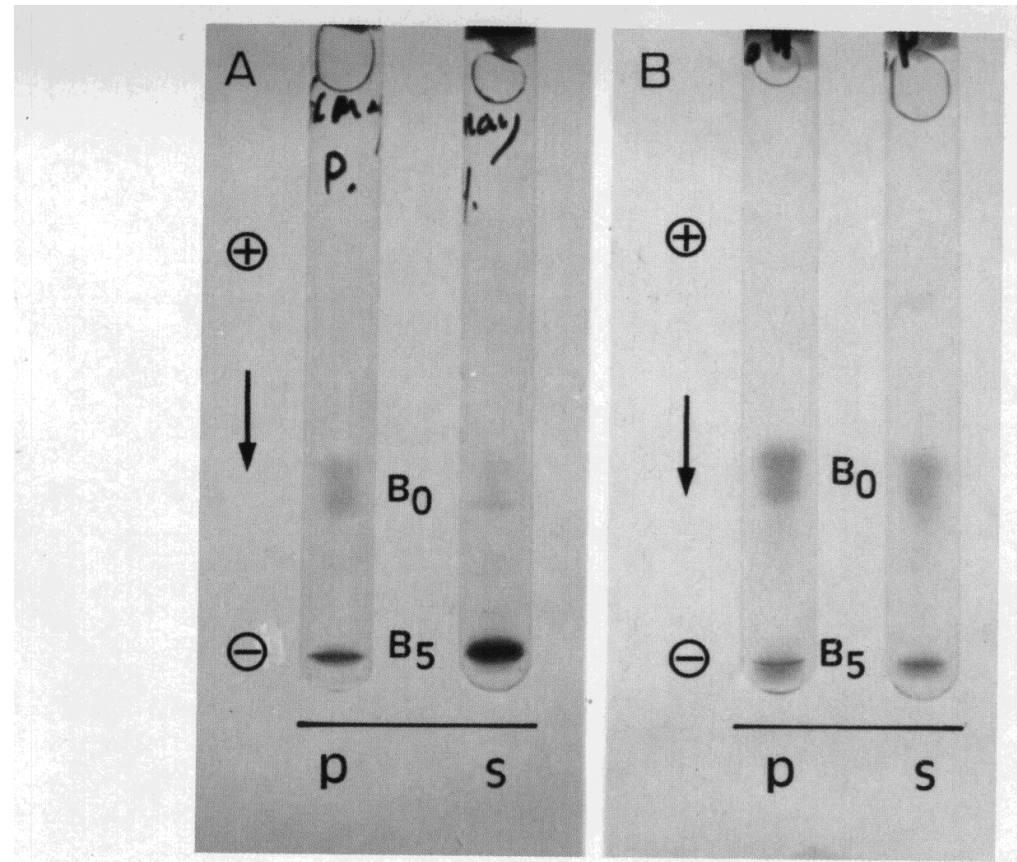

Fig. 2. Isoenzyme patterns of the peroxidase activity present in the skin (s) and pericarp (p) of mature 'Gamay' rouge (A) and immature 'Grenache' $(\mathbf{B})$ berries. Arrows indicate the direction of protein migration during isoelectrofocusing. 
oxidase activity found in the skin and pericarp of the two cultivars was analyzed by protein isoelectrofocusing in 3.5 to $10.0 \mathrm{pH}$ gradients. The peroxidase isoenzyme patterns of the skin and the pericarp were similar in both cultivars (Fig. 2). The pattern was characterized by the presence of two groups of peroxidase isoenzymes $\left(\mathrm{B}_{0}\right.$ and $\left.\mathrm{B}_{5}\right)$ that were previously in the grapevine vacuole (Calderón et al., 1992b) and whose main function apparently is vacuolar degradation of polyphenolic compounds such as anthocyanins (Calderón et al., 1992a)

In summary, blotting freezing/thawing grape sections on nitrocellulose membranes retains the vascular bundle structure; therefore, the internal anatomy of the grapes is maintained for histochemical peroxidase localization. This technique reveals that, in mature grapes, peroxidase-mediated reaction products are located mainly in the skin and, secondarily, in the pericarp, where discrete areas of reaction products are located in the vascular bundles. Thus, this technique may apply to highly hydrated tissues, such as grape berries, where a high resolution in the histochemical localization of peroxidase is desirable.

\section{Literature Cited}

Abeles, F.B. and C.L. Biles. 1991. Characterization of peroxidases in lignifying peach fruit endocarp. Plant Physiol. 95:269-273.
Calderón, A.A., E. García-Florenciano, R. Muñoz, and A. Ros Barceló. 1992a. Gamay grapevine peroxidase: Its role in vacuolar anthocyani(di)n degradation. Vitis 31:139-147.

Calderón, A.A., E. García-Florenciano, M.A. Pedreño, R. Muñoz, and A. Ros Barceló. 1992b. The vacuolar localization of grapevine peroxidase isoenzymes capable of oxidizing 4-hydroxystilbene. Z. Natursforsch. 47c:215221 .

Calderón, A.A., M.A. Pedreño, A. Ros Barceló, and R. Muñoz. 1990. Zymographic screening of plant peroxidase isoenzymes oxidizing 4-hydroxystilbenes. Electrophoresis 11:507508 .

Ferrer, M.A., A.A. Calderón, R. Muñoz, and A. Ros Barceló. 1990. 4-Methoxy $-\alpha-$ naphthol as a specific substrate for kinetic, zymographic and cytochemical studies on plant peroxidase activities. Phytochem. Anal. 1:63-69.

Haard, N.F. 1977. Physiological roles of peroxidase in postharvest fruits and vegetables. Amer. Chem. Soc. Symp. Ser. 47:143-171.

Hertig, C., G. Rebmann. J. Bull, F. Mauch, and R. Dudler. 1991. Sequence and tissue-specific expression of a putative peroxidase gene from wheat (Triticum aestivum L.). Plant Mol. Biol. 16:171-174.

Kahn, V. 1985. Tropolone-A compound that can aid in differentiating between tyrosinase and peroxidase. Phytochemistry 24:915-920.

Kochhar, S., V.K. Kochhar, and S.D. Khanduja. 1979. Changes in the pattern of isoperoxidases during maturation of grape berries cv Gulabi as affected by ethephon. Amer. J. Enol. Viticult 30:275-277.

Lagrimini, L.M., W. Burkhart, M. Moyer, and S. Rothstein. 1987. Molecular cloning of complementary DNA encoding the lignin-forming peroxidase from tobacco: Molecular analysis and tissue-specific expression. Proc. Natl. Acad. Sci. USA 84:7542-7546.

Moskowitz, A.H. and G. Hrazdina. 1981. Vacuolar content of fruit subepidermal cells from Vitis species. Plant Physiol. 68:686-692.

Nibbering, P.H., J.G.J. Marijnen, A.K. Raap, P.C.J. Leijh, and R. van Furth. 1986. Quantitative study of enzyme immunocytochemical reactions performed with enzyme conjugates immobilized on nitrocellulose. Histochemistry 84:538-543.

Pratt, C. 1971. Reproductive anatomy in cultivated grapes-A review. Amer. J. Enol. Viticult. 22:92-109.

Spruce, J., A.M. Mayer, and D.J. Osborne. 1987. A simple histochemical method for locating enzymes in plant tissue using nitrocellulose blotting. Phytochemistry 26:2901-2903.

Takahama, U. 1991. Purification and characterization of peroxidase in vacuoles of leave cells of Vicia faba, p. 205-207. In: J. Lobarzewski, H. Greppin, G. Penel, and Th. Gaspar (eds.). Molecular and physiological aspects of plant peroxidases. Univ. M. Curie-Sklodowska, Lublin, Poland.

Valero, E., M. Garcia-Moreno, R. Varón, and F. García-Carmona. 1991. Time-dependent inhibition of grape polyphenoloxidase by tropolone. J. Agr. Food Chem. 39:1043-1046. 